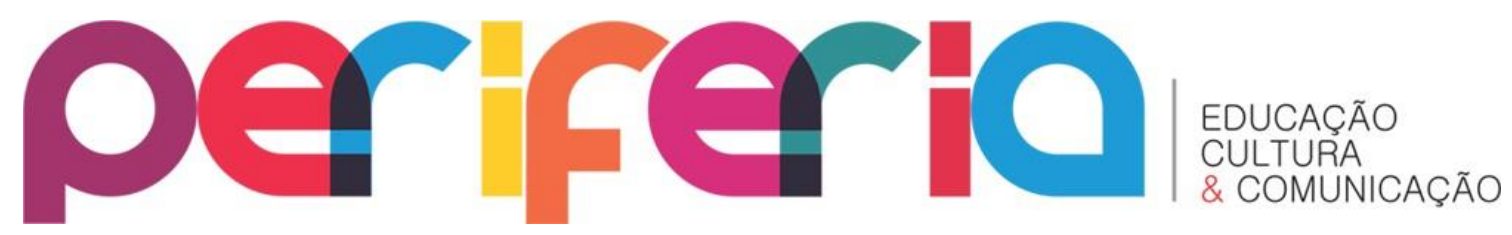

\title{
A EDUCAÇÃO SEXUAL NA PRIMEIRA INFÂNCIA: ELEMENTOS PARA UMA ABORDAGEM PÓS-ESTRUTURALISTA
}

\author{
Michele Ignacio Pires ${ }^{1}$
}

Universidade do Estado do Rio de Janeiro

\section{RESUMO}

Este artigo aborda a Educação Sexual na educação infantil. Apoia-se nas reflexões sobre o tema apresentadas por Jimena Furlani e nas ponderações pós-críticas desenvolvidas por Ernesto Laclau e Chantal Mouffe quanto à identidade como algo fluido, constituído num processo de associações contingentes e precárias. Questiona as significações hegemônicas sobre Direitos Humanos e argumenta em favor da ressignificação do termo, conforme desenvolvido por Aura Helena Ramos, para quem esse é um campo de disputas e negociações permanentes. O estudo busca identificar elementos para uma abordagem da Educação Sexual que alicerce ações pedagógicas voltadas ao questionamento do determinismo biológico e o reconhecimento e respeito radical às diferenças de gênero, orientação sexual, étnico-raciais, religiosas etc.

Palavras-chave: Educação infantil, Educação Sexual, Educação em Direitos Humanos.

\section{THE SEX EDUCATION IN EARLY CHILDHOOD: ELEMENTS OF A POST-STRUCTURALIST APPROACH}

\section{ABSTRACT}

The article deals with sex education in kindergarten. It is based on reflections on the theme presented by Jimena Furlani and post-critical considerations developed by Ernesto Laclau and Chantal Mouffe regarding to the identity as something fluid, constituted in a process of contingent and precarious associations. Discusses the hegemonic meanings on Human Rights and argues for the redefinition of the term, as developed by Aura Helena Ramos, according to which this is a field of disputes and permanent negotiations. The study seeks to identify elements for an approach to sex education that support pedagogical actions focused at questioning the biological determinism and the recognition and radical respect to gender differences, sexual orientation, ethnic-racial, religious etc.

Keywords: Early Childhood Education; Sex Education; Human Rights Education.

\footnotetext{
${ }^{1}$ Pedagoga e professora. Mestranda e membro do grupo de pesquisa Currículo, Formação e Educação em Direitos Humanos, vinculado ao Programa de Pós-Graduação em Educação, Cultura e Comunicação em Periferias Urbanas da Faculdade de Educação da Baixada Fluminense, da Universidade do Estado do Rio de Janeiro. E-mail: michelepires@gmail.com
} 


\section{periferio}

\section{INTRODUÇÃO}

O presente artigo é parte de estudo em desenvolvimento que investiga o modo como a temática da Educação Sexual é tratada em salas de aula da educação infantil. 0 estudo tem como objeto o processo de desenvolvimento e manifestação da sexualidade nos primeiros anos de vida e a capacitação, ou não, que os professores têm para lidar com essa questão. Refletimos sobre Educação Sexual em uma proposta de reconhecimento das diferenças segundo uma visão pós-crítica. Do ponto de vista pedagógico, tal abordagem é favorecida pela perspectiva de Educação em Direitos Humanos fundada no compromisso com a constituição de espaços e canais de manifestação e negociação da diferença - de orientação sexual, de gênero, de raça e etnia, de crenças religiosas etc.

Neste texto, objetivamos trazer as reflexões teóricas que orientam o referido estudo e nos tem permitido problematizar questões relativas à educação sexual em situações pedagógicas voltadas à primeira infância.

A partir da Constituição de 1988, a criança brasileira de 0 a 6 anos começa a ser considerada sujeito de direitos, para quem o Estado deveria garantir educação. Logo após, em 1990, surgiu o Estatuto da Criança e do Adolescente, outro marco que permitiu que a criança fosse englobada como cidadã partícipe dos Direitos Humanos. Enfim, em 1996, a educação infantil apareceu na nova Lei de Diretrizes e Bases (LDB) como primeira etapa da educação básica, responsável por promover o desenvolvimento integral da criança até seis anos de idade e complementar a ação da família e da comunidade (BRASIL, 1996).

A inserção da educação infantil na educação básica representou o reconhecimento da importância e das vantagens da educação formal desde a primeira infância e abriu espaço para outras regulamentações importantes, como o Referencial Curricular Nacional para a Educação Infantil (BRASIL, 1998).

Após esse brevíssimo recorte histórico da educação infantil em nosso país, é possível dar um passo adiante nas reflexões sobre a temática inicial. 


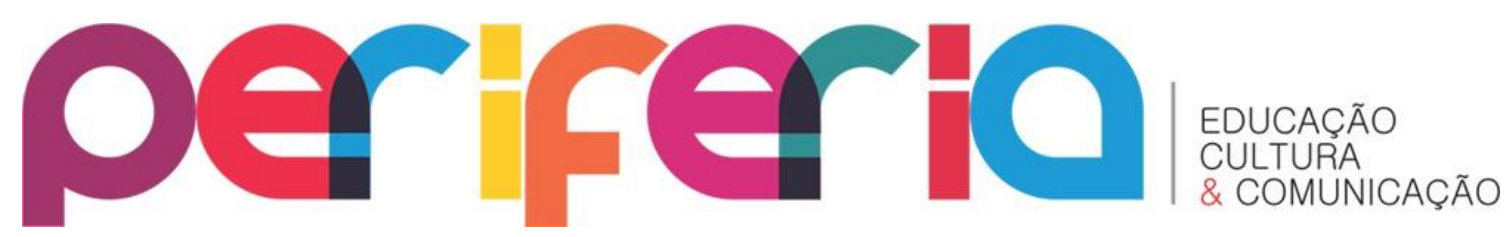

Constata-se que a criança passa a ser apreciada como sujeito de direitos e há preocupação com seu desenvolvimento integral, sendo destacada inclusive a necessidade de as crianças desenvolverem a capacidade de conhecer e respeitar seu próprio corpo, "desenvolvendo e valorizando hábitos de cuidado com a própria saúde e bem-estar" (BRASIL, 1998, p. 63, v. 1).

É dificílimo pensar sobre desenvolvimento integral do ser sem citar os processos de descoberta, desenvolvimento e manifestações da sexualidade desde os primeiros anos de vida. As instituições de educação infantil, responsáveis, como já foi dito, por complementar a ação da família e da comunidade na formação de cidadãos íntegros, devem participar com os seus alunos desse processo de vivência da sexualidade de maneira saudável, recebendo suas dúvidas e interesses e ensinando o respeito ao próprio corpo e ao corpo do outro, favorecendo, além disso, o respeito à diversidade.

Segundo Vygotsky (1996), a criança, como todo ser humano, é um sujeito biológico, social e histórico, que se constitui na interação com o outro no espaço social. Ora, se as crianças se desenvolvem na troca com o coletivo, as salas de aula de educação infantil podem ser consideradas espaços privilegiados no que diz respeito às possibilidades de construção de uma Educação Sexual baseada, como será proposto nesse trabalho, em uma abordagem dos Direitos Humanos (Furlani, 2011). Tal abordagem é caracterizada pelo compromisso com a construção de uma sociedade que respeite as diferenças sexuais, de gênero, de raça e etnia, de crenças religiosas, de classe social etc.

Desde a abordagem da educação infantil como um segmento constitutivo da escolaridade formal até o tratamento de temas relacionados à sexualidade como pertinentes à infância, estamos diante de questões sobre as quais a escola tem uma experiência muito recente. Se a exigência de formação pedagógica para educadores que atuam na educação infantil é algo que ainda é um projeto por se realizar, faz sentido nos indagarmos sobre que condições esses profissionais possuem para tratar 


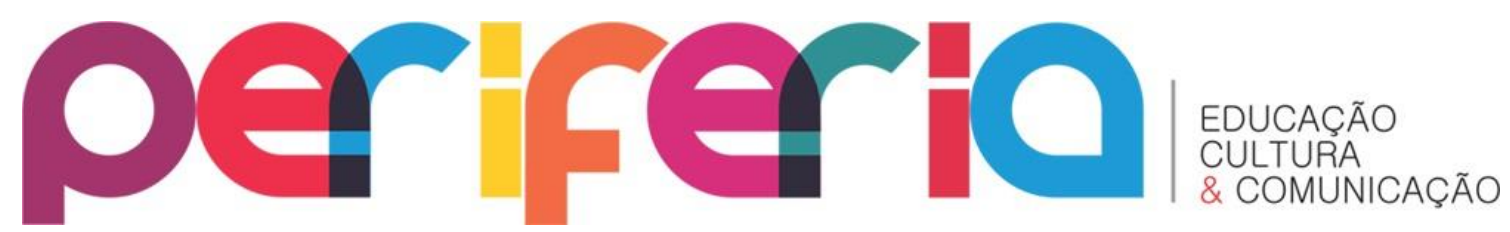

de forma adequada a sexualidade infantil e suas primeiras manifestações e delimitar os princípios norteadores de suas ações de forma consciente.

É necessário, portanto:

[...] discutir, como primeiro ponto, o direito à Educação Sexual. Nesse sentido, mesmo que reconheçamos que os cursos de formação não habilitem adequadamente professoras/es para o trabalho de Educação Sexual na escola, a formação continuada pode e deve buscar suprir essa lacuna (FURLANI, 2011, p. 28).

Nesse ponto, é relevante contextualizar o interesse em pesquisar a temática apresentada, explicitando as motivações que estão intrinsecamente ligadas à minha própria trajetória profissional.

Como professora concursada do município de Duque de Caxias, no Estado do Rio de Janeiro, desde 2006 atuo em educação infantil na Creche Municipal Professora Laura D’Aquino Longo, tendo especial interesse em questões relacionadas à Educação em Direitos Humanos. Tais questões não são devidamente trabalhadas em salas de aula da educação infantil, quando seria esse um ambiente propício, já que se constitui como primeiro espaço de socialização após a família.

Primeiramente, a sexualidade é um elemento humano que se refere à descoberta corporal e afetiva, ao prazer, ao autoconhecimento e cujas manifestações e efeitos são aqui considerados construções discursivas que se manifestam desde o nascimento até o fim da vida. Assim, espera-se que a escola inclua em seus currículos a Educação Sexual em todos os níveis de escolarização, com o objetivo de formar crianças sexualmente saudáveis. Em minha experiência como educadora no município de Duque de Caxias, não foi possível verificar que tal afirmativa se traduza em realidade na educação infantil, constituindo motivação para o presente estudo. Nesse sentido, podemos citar Haffner (2005, p. 20), que elenca alguns pontos para que crianças sejam consideradas sexualmente saudáveis: "se sentem bem com seus corpos"; "entendem o conceito de privacidade"; "tomam decisões adequadas à sua idade"; "ficam à vontade para fazer perguntas" e "se sentem preparadas para a puberdade". 


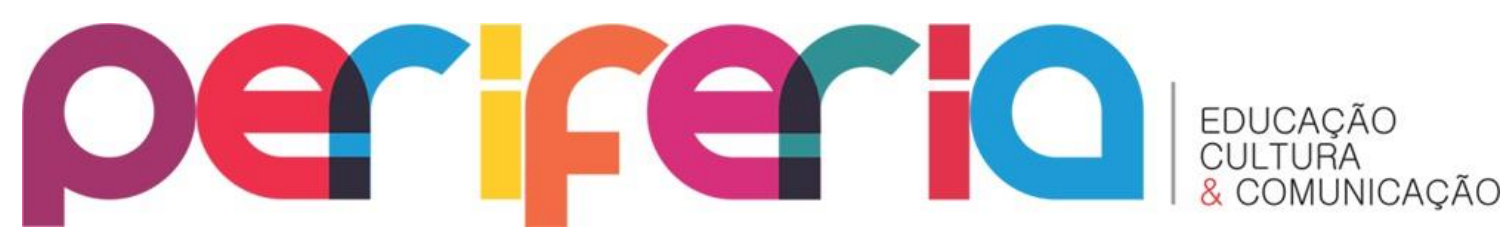

Além disso, também é fundamental salientar o segundo ponto que motiva o presente trabalho: a partir de observação durante meus anos de experiência em educação infantil em Duque de Caxias, foi possível constatar que questões recorrentes entre os alunos relacionadas à percepção do próprio corpo, descobrimento do prazer genital, reprodução de estereótipo de gênero e preconceitos, dúvidas sobre a concepção dos bebês e sobre a dinâmica das relações afetivas etc. geralmente são tratadas com ênfase no senso comum ou em opiniões individuais.

A partir da compreensão da importância da Educação Sexual nas salas de aula, faz-se necessário ainda reconhecer que a multiplicidade de discursos contemporâneos sobre sexualidade torna imperativa a definição de um referencial teórico que possa delimitar os princípios norteadores das ações pedagógicas de forma consciente. Tal definição não é apenas conceitual, já que reflete uma disputa de saberes e significados e implica um posicionamento político.

A falta de continuidade e investimento na formação continuada dos professores não favorece uma tomada de decisão a partir da reflexão qualificada sobre os discursos existentes e que permita contestar os padrões muitas vezes naturalizados na sociedade. $\mathrm{Na}$ atualidade, se faz cada vez mais imperativa a construção de novos paradigmas para a educação que apresentem respostas mais apropriadas para a complexa problemática de nosso tempo.

Furlani (2011, p. 15) apresenta algumas abordagens de Educação Sexual, ponderando que o profissional docente, em sua prática, não costuma considerar necessária a definição de um referencial teórico que o oriente e contra-argumenta:

Debruçar o olhar, teórico e didático, sobre essas abordagens tem uma grande implicação educativa e política para o trabalho docente. Entendo que cada uma delas pressupõe uma concepção de educação, um entendimento de sexualidade e de vida sexual humana, um entendimento de valores morais e éticos de vida em sociedade, um entendimento de direitos e de sujeitos merecedores desses direitos e, sobretudo, cada uma dessas abordagens define a prática docente e o perfil da/o professora/or que pensará, planejará e desenvolverá essa educação sexual. 


\section{periferio}

EDUCAÇÃO SEXUAL EM UMA PROPOSTA DE RECONHECIMENTO DAS DIFERENÇAS EM UMA PERSPECTIVA PÓS-CRÍTICA

A Educação Sexual abordada pela perspectiva dos Direitos Humanos implica ações pedagógicas voltadas para o questionamento do contexto social, cultural e político em que vivemos. Segundo Furlani (2011), tal abordagem está dentre as que mais se aproximam do "reconhecimento da diferença como positiva e benéfica a um mundo que se encontra no terceiro milênio" (p. 23).

Os Estudos Culturais e o Pós-Estruturalismo alicerçaram reflexões sobre as diferentes identidades culturais e de como a classe social não era a única nem a mais importante explicação para os processos de desigualdade e exclusão social. Sendo assim, a discussão dos Direitos Humanos relativas à exclusão ganharam novos contornos e,

[...] a partir da segunda metade do século $X X$, principalmente os movimentos sociais mostraram que os mecanismos de desigualdades e injustiças articulavam-se a múltiplos marcadores sociais: sexo, gênero, sexualidade, raça, classe, geração.

Dentre esses marcadores, os homens e as mulheres pertencentes às identidades subordinadas tinham não apenas seu estado de "sujeito de direitos" violados, mas também eram "vítimas" de específicos modos de discriminação, preconceito e violência, decorrentes de cada identidade cultural (FURLANI, 2011, p. 24).

Essas questões relacionam-se intrinsecamente com a educação formal, já que se considera "o contexto educacional como campo não apenas de produção e reprodução das representações excludentes, mas também como local de contestação e resistência de grupos subordinados" (FURLANI, 2011, p. 23).

Sendo assim, a proposta aqui exposta tem apoio na abordagem de Educação Sexual dos Direitos Humanos apresentada por Furlani (2011), considerando ser a que nos aproxima do intento de alcançar uma Educação Sexual voltada para o reconhecimento das diferenças e das ponderações teóricas sobre a constituição do social na perspectiva pós-crítica desenvolvida por Ernesto Laclau e Chantal Mouffe, quando afirmam identidade como algo fluido, constituído em um processo de associações contingentes e precárias. 


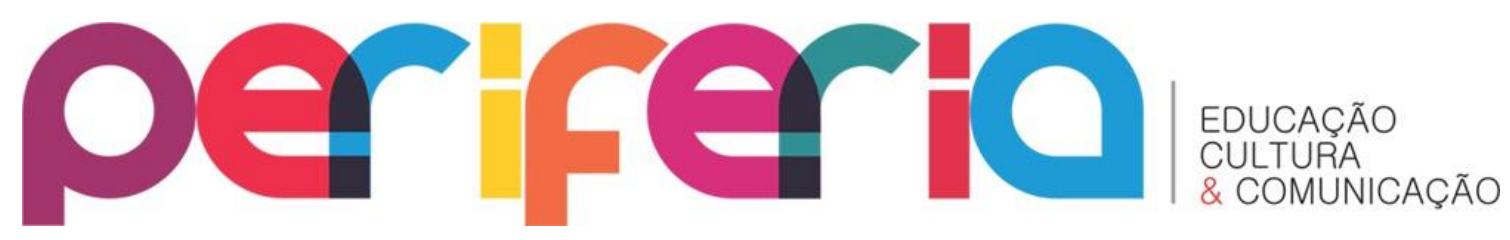

Tal opção por um enfoque dos Direitos Humanos reflete uma contingência histórica nas discussões sobre a sexualidade, podendo ser considerada uma opção contingente, temporária, nos termos de uma visão pós-crítica que será mais desenvolvida a seguir.

Ao tratar da Teoria do Discurso de Ernesto Laclau como base teórica para uma análise do social, Burity (2008) elucida o conceito de discurso como uma forma de comunicação no contexto social e como unidade de significação que vai além da frase como um sistema de regras de produção social de sentido, e acrescenta que "poderse-ia dizer que, no trabalho de Ernesto Laclau, o conceito de discurso vai ser introduzido numa reflexão sobre a política para dar conta, inicialmente, do lugar que a questão do sentido precisa ter numa reflexão sobre a ação social" (BURITY, 2008, p. 37).

Partindo de uma crítica ao marxismo, as contribuições teóricas de Laclau e Mouffe rejeitam a ideia de um sujeito cuja classe social é o marcador que define sua condição humana e determina os processos de desigualdade e exclusão social. Apresentam, então, uma nova concepção sobre a identidade constitutiva dos sujeitos sociais que "são interpelados por muitas identidades culturais, ou seja, cada pessoa apresenta distintos e múltiplos aspectos identitários. Essas identidades são construídas discursivamente nos processos que instituem a diferença" (FURLANI, 2011, p. 49).

Sendo assim, a classe social não é mais o ponto central e determinante na análise do social da Teoria do Discurso. Conforme citado, outros aspectos diversos marcam os sujeitos socialmente, como questões de gênero, orientação sexual, raça, etnia, religião, geração etc. $E$ esses aspectos são contingentes, temporários e precários, sempre caracterizados por disputas de sentido que estão presentes na sociedade. Hall (2000, p. 112) acrescenta que "as identidades são, pois, pontos de apego temporários às posições de sujeito que as práticas discursivas constroem para nós".

Para Laclau e Mouffe, a constituição do social se dá simbolicamente, ou seja, "o sentido é coconstitutivo da realidade social, de modo que se pode dizer, sem qualquer 


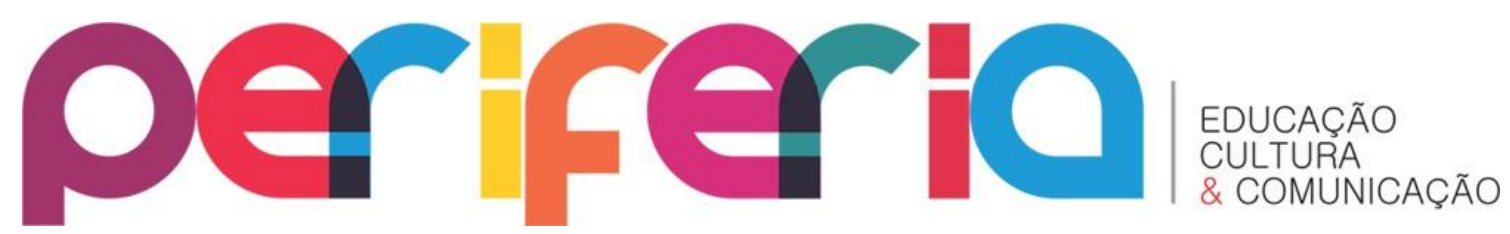

associação com uma postura idealista, que não há nenhuma realidade social sem (o) sentido" (BURITY, 2008, p. 38).

Mas e quanto aos conceitos de escola e de direitos humanos? Tais conceitos são compatíveis com uma proposta de Educação Sexual que respeite a diferença como construção discursiva?

Segundo Ramos (2011, p. 23), os conceitos de escola e de direitos humanos são "construções discursivas que a hegemonia moderna universalizou" e que necessitam ter sua significação hegemônica questionada, já que a realidade contemporânea é caracterizada "por problemas que a modernidade não foi capaz de equacionar".

Os termos escola e direitos humanos foram significados por um alicerce moderno marcado por uma busca pela universalidade de direitos e igualdade, aspectos que necessitam ser destacados

[...] por funcionar como estratégias discursivas associadas a práticas de subordinação do outro, para o qual o mesmo é o modelo descrito pela racionalidade moderna ocidental. Entendemos que essa é uma marca da qual a abordagem critica não consegue se desprender e em função da qual produz uma ideia de direitos humanos e de política cultural (nomeadamente as escolares) que se caracteriza, tanto quanto a versão liberal, por práticas de regulação e controle da diferença (RAMOS, 2011, p. 24).

Em outras palavras: os conceitos de escola e direitos humanos ainda refletem um forte discurso moderno universalista que se traduz em uma promessa de alcance do consenso e promoção da igualdade em um molde cristão ocidental, apesar de esse intento nunca ter sido obtido a partir desses pressupostos.

A realidade social é constituída pela produção de sentido. Podemos afirmar, por conseguinte, que a apreensão possível acerca da escola e dos direitos humanos passa, obrigatoriamente, pela significação desses termos em um dado momento, o que se dá de maneira contingencial, temporária e precária, de acordo com o pensamento hegemônico do período histórico (RAMOS, 2011).

Ramos (2011) propõe, então, um questionamento dessas práticas discursivas a partir de uma ressignificação desses termos, construindo por meio de um processo constante de disputa de significação um entendimento de direitos humanos e escola 


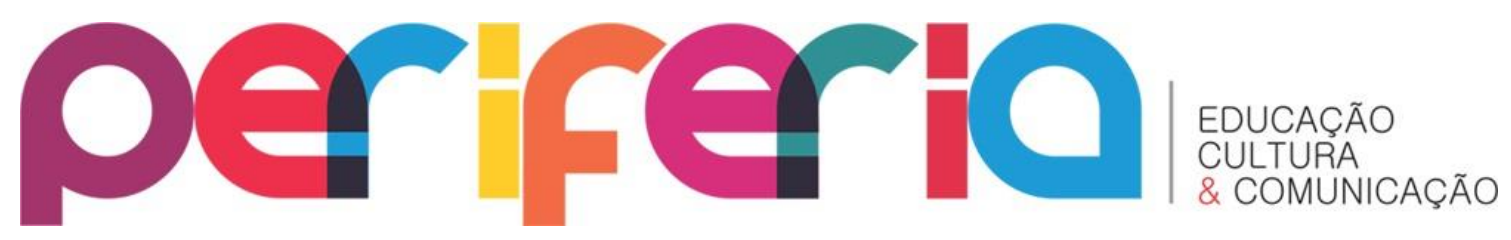

como espaços de expressão da diferença mais adequados ao mundo contemporâneo, nos quais emergem questões para além da categoria de classes sociais.

A escola, na definição moderna, ainda é espaço de reprodução de padrões com referenciais do século $X X$ que perpassam as práticas docentes. Porém a realidade mostra que nela, como na sociedade como um todo, existem várias identidades (hegemônicas e não hegemônicas) que constituem os sujeitos da educação naquele momento e precisam ser levadas em consideração e valorizadas.

Assim, a escola e a Educação Sexual em Direitos Humanos, ressignificadas, podem recusar e/ou problematizar os padrões estabelecidos e considerados universais.

Cabe-nos, então, considerar que

[...] a escola de hoje não pode, apenas, querer "transmitir os conhecimentos sistematizados historicamente pela humanidade" até porque, como esses conhecimentos foram construídos em relações desiguais de poder, eles, certamente, não incluem todos os sujeitos humanos nem são conhecimentos representativos de todas as identidades culturais. A escola precisa incluir na sua agenda pedagógica a multiplicidade cultural, os saberes populares advindos de movimentos sociais e os saberes advindos das experiências subjetivas dos sujeitos (FURLANI, 2011, p. 52).

A educação sexual fundamentada nesses alicerces, vale ressaltar, é assumidamente política e vai contra a ideia da escola como espaço de neutralidade. Além de o processo educativo não ser encarado como iniciativa neutra, precisa refletir uma prática política por mudança. Assim,

[...] a suposta neutralidade política escolar é definitivamente posta em xeque. O momento atual aponta para um processo escolar que, em todos os níveis (inclusive nos cursos de formação de educadoras/es), esteja minimamente articulado com políticas públicas que possam combater e minimizar as injustiças e as desigualdades sociais (FURLANI, 2011, p. 23).

Nesse sentido, a Educação Sexual abordada pela ótica dos Direitos Humanos "é aquela que fala, explicita, problematiza e destrói as representações negativas socialmente impostas aos sujeitos e às suas identidades 'excluídas'”' (FURLANI, 2011, p. 24) e tem como compromisso a construção de uma sociedade menos desigual e mais 


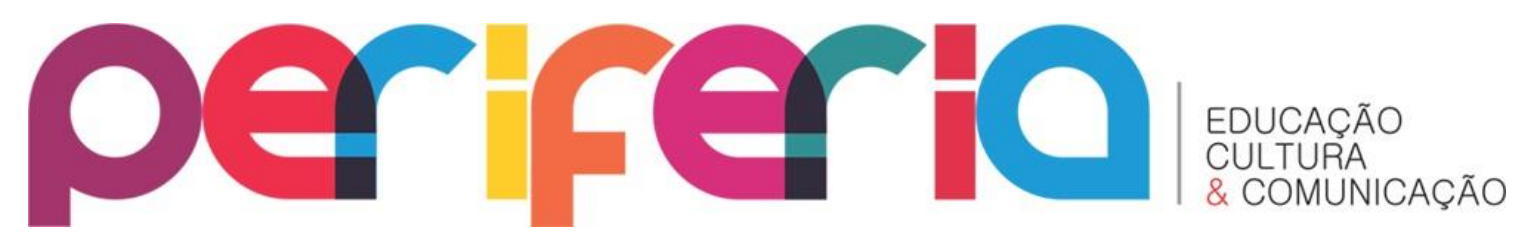

humana. Um dos primeiros passos para tal consiste em dialogar sobre o respeito ao próprio corpo e ao corpo do outro, promovendo o reconhecimento da diversidade.

Na educação formal brasileira, o discurso homogêneo acerca da educação sexual baseia-se na biologia essencialista, possui um enfoque exclusivo na promoção da saúde e estudo da reprodução humana e é fundamentado no determinismo biológico. Segundo Furlani (2011), as premissas do determinismo biológico contribuíram e ainda contribuem para "a naturalização das desigualdades sexuais e de gênero". Para Guacira Louro (1999), a predominância dessa perspectiva pode, inclusive, "rodear o exercício da sexualidade de uma aura de perigo e de doença" ( $p$. 140).

Outro aspecto importante para ressaltarmos é que essa abordagem reforça a opinião de que a Educação Sexual teria como público-alvo os adolescentes, não levando em consideração as inúmeras vantagens de formar pessoas sexualmente saudáveis desde a infância.

Observando, ainda, as práticas disseminadas na educação formal brasileira, Guacira Louro (2005) reflete sobre como as variadas identidades chamadas comumente de "minorias" são apreciadas:

Professoras e professores bem-intencionados se esforçam para listar as "contribuições" desses grupos para o país. [...] Com tais providências, dá-se por atendida a tal ausência reclamada. [...] As atividades [...] não chegam a perturbar o curso "normal" dos programas, nem mesmo servem para desestabilizar o cânon oficial (p. 45).

Pode-se concluir, então, que são somente

[...] estratégias que podem tranquilizar a consciência dos planejadores, mas que, na prática, acabam por manter o lugar especial e problemático das identidades "marcadas" e, mais do que isso, acabam por apresentá-las a partir das representações e narrativas construídas pelo sujeito central (LOURO, 2005, p. 45).

Na verdade, o que se propõe no presente estudo para contrapor às práticas supracitadas é uma postura pedagógica de questionamento aos padrões hegemônicos 


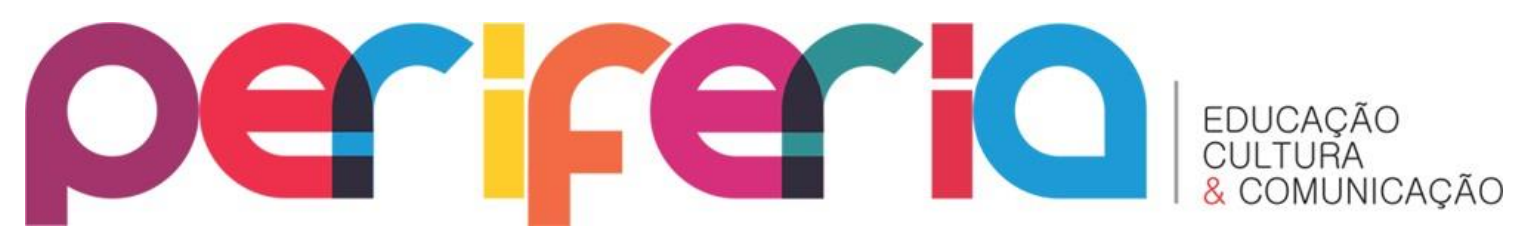

e a promoção de espaços nas escolas onde o conflito seja legitimado e a diferença, vista como benéfica. A educação sexual seria constituída com o objetivo de

[...] demonstrar como a produção da normalidade é intencional, histórica, política e, sendo assim, instável, contingencial, questionável e mutável [...]; problematizar as redes de poder e os interesses que definem as representações negativas, inferiores e propositadamente excluídas dos currículos acerca de gênero, sexualidade, das raças e etnias (FURLANI, 2011, p. 37).

\section{CONSIDERAÇÕES FINAIS}

Os conceitos teóricos elucidados nesse artigo necessitam ser cogitados na prática, com ações docentes planejadas e alicerçadas em uma visão pós-crítica. Essa concepção, entretanto, não tem a pretensão de ser considerada solução definitiva para os problemas, o que estaria inclusive na contramão das teorizações pós-críticas ou pós-estruturalistas, já que o "pós-estruturalismo não possui qualquer pretensão em ser propositivo, pragmático. Pelo contrário [...]. Apontar caminhos únicos, dentro desse referencial, pode ser visto por muitos/as de seus/suas teóricos/as como completa incoerência teórica" (FURLANI, 2011, p. 66).

Na prática, a proposta problematiza e questiona constantemente as relações de poder e padrões normativos e não define posturas metodológicas fixas. A ação precisa ser voltada para a promoção da diferença como algo valorizado e refletir a precariedade e a instabilidade de todas as identidades. Furlani (2011, p. 38) analisa:

Como pode a Educação discursar sobre sua importância nos processos de combate a desigualdades sociais, na busca pela proclamada cidadania plena, se o seu currículo não oferece aos/às alunos/as e aos/às professores/as as representações de todas as identidades - inclusive as suas?

Assim, a comunidade escolar estaria aberta para discutir porque algumas identidades são aceitas e valorizadas, enquanto outras são negadas e excluídas. Poderíamos investir em um cenário mais favorável para que os alunos, ao longo de sua formação, possam compreender que as "verdades" e padrões são discursivamente produzidos e devem ser problematizados. 


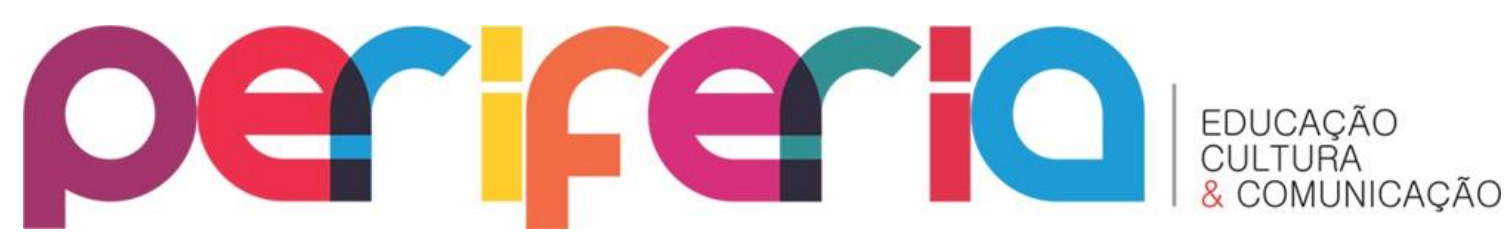

Um passo importante nessa proposta de educação sexual, portanto, é promover, desde a educação infantil, a visibilidade e a valorização de identidades subordinadas e o questionamento dos discursos homogêneos.

\section{REFERÊNCIAS}

BRASIL. Constituição da República Federativa do Brasil. Brasília: Senado Federal, 1988. . Estatuto da Criança e do Adolescente. Lei no 8.069, de 13 de junho de 1990. - Ministério da Educação e Cultura. Lei de Diretrizes e Bases da Educação Nacional. Lei no 9.394, de 20 de dezembro de 1996. Dispõe sobre as Diretrizes e Bases da Educação Nacional. Brasília: MEC, 1996.

Ministério da Educação e do Desporto. Secretaria de Educação Fundamental. Referencial curricular nacional para a educação infantil. Brasília: MEC/SEF, 1998.

BURITY, Joanildo A. Discurso, política e sujeito na teoria da hegemonia de Ernesto Laclau. In: MENDONÇA, Daniel de; RODRIGUES, Léo Peixoto (orgs). Pós-Estruturalismo e Teoria do Discurso: em torno de Ernesto Laclau. Porto Alegre: EDIPUCRS, 2008.

FURLANI, Jimena. Educação Sexual na sala de aula: relações de gênero, orientação sexual e igualdade étnico-racial numa proposta de respeito às diferenças. Belo Horizonte: Autêntica Editora, 2011.

HAFFNER, Debra W. A criança e a educação sexual. Lisboa: Presença, 2005.

HALL, Stuart. Identidade cultural na pós-modernidade. Rio de Janeiro: DP\&A, 2000.

LOURO, Guacira Lopes. Gênero, sexualidade e educação - Uma perspectiva pósestruturalista. 3a ed. Petrópolis: Vozes, 1999.

LOURO, Guacira Lopes. Currículo, gênero e sexualidade - refletindo sobre o "normal", o "diferente" e o "excêntrico". In: LOURO, Guacira Lopes; NECKEL, Jane Felipe; GOELLNER, Silvana V. (orgs.). Corpo, gênero e sexualidade - um debate contemporâneo em educação. 2ª ed. Petrópolis: Vozes, 2005.

RAMOS, Aura Helena. O lugar da diferença no currículo de Educação em Direitos Humanos. Rio de Janeiro: Quartet/Faperj, 2011.

VYGOTSKY, Lev S. A formação social da mente. Rio de Janeiro: Martins Fontes, 1996. 